\title{
The El Niño event of 2015-2016: climate anomalies and their impact on groundwater resources in East and Southern Africa
}

\author{
Seshagiri Rao Kolusu ${ }^{1}$, Mohammad Shamsudduha ${ }^{2,3}$, Martin C. Todd ${ }^{1}$, Richard G. Taylor ${ }^{2}$, David Seddon ${ }^{2}$ \\ Japhet J. Kashaigili ${ }^{4}$, Girma Y. Ebrahim ${ }^{5}$, Mark O. Cuthbert ${ }^{2,6}$, James P. R. Sorensen ${ }^{7}$, Karen G. Villholth ${ }^{5}$, \\ Alan M. MacDonald ${ }^{8}$, and Dave A. MacLeod ${ }^{9}$ \\ ${ }^{1}$ Department of Geography, University of Sussex, Brighton, BN1 9QS, UK \\ ${ }^{2}$ Department of Geography, University College London, Gower Street, London, WC1E 6BT, UK \\ ${ }^{3}$ Institute for Risk and Disaster Reduction, University College London, Gower Street, London, WC1E 6BT, UK \\ ${ }^{4}$ Sokoine University of Agriculture, Morogoro, Tanzania \\ ${ }^{5}$ International Water Management Institute, Pretoria, South Africa \\ ${ }^{6}$ School of Earth and Ocean Sciences, Cardiff University, Main Building, Park Place, Cardiff, CF10 3AT, UK \\ ${ }^{7}$ British Geological Survey, Maclean Building, Crowmarsh Gifford, Wallingford, Oxfordshire, OX10 8BB, UK \\ ${ }^{8}$ British Geological Survey, The Lyell Centre, Research Avenue South, Edinburgh, EH14 4AP, UK \\ ${ }^{9}$ Atmospheric, Oceanic and Planetary Physics, University of Oxford, Oxford, OX1 3PU, UK
}

Correspondence: Seshagiri Rao Kolusu (s.kolusu@sussex.ac.uk, seshukolusu@gmail.com)

Received: 3 October 2018 - Discussion started: 8 October 2018

Revised: 16 January 2019 - Accepted: 13 March 2019 - Published: 29 March 2019

\begin{abstract}
The impact of climate variability on groundwater storage has received limited attention despite widespread dependence on groundwater as a resource for drinking water, agriculture and industry. Here, we assess the climate anomalies that occurred over Southern Africa (SA) and East Africa, south of the Equator (EASE), during the major El Niño event of 2015-2016, and their associated impacts on groundwater storage, across scales, through analysis of in situ groundwater piezometry and Gravity Recovery and Climate Experiment (GRACE) satellite data. At the continental scale, the El Niño of 2015-2016 was associated with a pronounced dipole of opposing rainfall anomalies over EASE and Southern Africa, north-south of $\sim 12^{\circ} \mathrm{S}$, a characteristic pattern of the El Niño-Southern Oscillation (ENSO). Over Southern Africa the most intense drought event in the historical record occurred, based on an analysis of the cross-scale areal intensity of surface water balance anomalies (as represented by the standardised precipitation evapotranspiration index - SPEI), with an estimated return period of at least 200 years and a best estimate of 260 years. Climate risks are changing, and we estimate that anthropogenic warming only (ignoring changes to other climate variables, e.g. precipitation) has approximately doubled the risk of such an extreme
\end{abstract}

SPEI drought event. These surface water balance deficits suppressed groundwater recharge, leading to a substantial groundwater storage decline indicated by both GRACE satellite and piezometric data in the Limpopo basin. Conversely, over EASE during the 2015-2016 El Niño event, anomalously wet conditions were observed with an estimated return period of $\sim 10$ years, likely moderated by the absence of a strongly positive Indian Ocean zonal mode phase. The strong but not extreme rainy season increased groundwater storage, as shown by satellite GRACE data and rising groundwater levels observed at a site in central Tanzania. We note substantial uncertainties in separating groundwater from total water storage in GRACE data and show that consistency between GRACE and piezometric estimates of groundwater storage is apparent when spatial averaging scales are comparable. These results have implications for sustainable and climate-resilient groundwater resource management, including the potential for adaptive strategies, such as managed aquifer recharge during episodic recharge events. 


\section{Introduction}

The El Niño-Southern Oscillation (ENSO) phenomenon is the dominant single driver of inter-annual climate variability and large-scale extremes across the tropics, including much of Africa. Few studies have investigated the hydrological impacts of ENSO events on groundwater. Here, we quantify climate anomalies and groundwater resources over East Africa, south of the Equator (EASE), and Southern Africa (SA) during the recent major El Niño event of 2015-2016, which was one of the strongest on record in the Pacific sector. El Niño is typically associated with wet and dry anomalies over EASE and SA, respectively (Ropelowski and Halpert, 1987), but with considerable diversity in this response among El Niño events, in part related to the many other drivers of variability active over EASE and SA (Sect. S1 in the Supplement). Much of SA experienced extreme drought in 2015-2016, with severe impacts on local food security, livelihoods and key sectors of the economy (SADC, 2016a, b; Archer et al., 2017; Siderius et al., 2018; Sect. S1).

Groundwater is the dominant source of safe water for rural populations and many expanding cities in EASE and SA (MacDonald et al., 2012); in drylands, groundwater is often the only perennial source of water. Although relatively underdeveloped to date, groundwater resources are being developed rapidly in Africa (Taylor et al., 2009; Calow et al., 2010; Villholth, 2013) and are featured prominently in national development plans, especially to satisfy the need for increased access to safe water and agricultural intensification under rapidly growing populations and economic development. Groundwater is especially important in Africa, where surface runoff efficiency is lower than elsewhere (McMahon et al., 1987) and drinking untreated surface water is associated with poor health (Hunter et al., 2010). The long-term viability of groundwater withdrawals and the livelihoods and ecosystems that groundwater sustains depend on recharge.

Unlike surface water, research evaluating associations between groundwater storage and ENSO, or indeed other modes of climate variability, is rather limited (e.g. Holman et al., 2011; Kuss and Gurdak, 2014), despite evidence that climate variability and extreme rainfall preferentially drive or restrict groundwater recharge. Several studies have shown recharge to be episodic in semi-arid regions of Africa (Meyer, 2005; van Wyk et al., 2011; Taylor et al., 2013; Cuthbert et al., 2017) and elsewhere (Jasechko and Taylor, 2015; Cuthbert et al., 2016), highlighting the need to understand patterns and drivers of climate variability, both temporally and spatially, that influence recharge. Bonsor et al. (2018) analysed recent (2002-2016) trends in, and seasonality of, groundwater storage within 12 African sedimentary basins implied from Gravity Recovery and Climate Experiment (GRACE) satellite data. Here, we employ evidence from both in situ observations (piezometry) and GRACE satellite data to examine the effect of large-scale inter-annual climate anomalies on groundwater across spatial scales for locations and domains that represent the rainfall anomaly gradient over EASE and SA associated with characteristic El Niño response, exemplified by the event of 2015-2016. Beyond a few site-specific studies, the impacts of larger-scale climate extremes on groundwater remain substantially unresolved. This hinders our ability to determine acceptable levels of groundwater abstraction and depletion. This study aims to quantify and understand the responses, during the 20152016 El Niño of (i) the surface or terrestrial water balance and (ii) groundwater storage over EASE and SA from regional to local scales. Further, it seeks to place the 20152016 El Niño event statistically in the historical context.

\section{Data and methods}

\subsection{Climate data and analysis}

We analyse data over the broad region of Africa that lies to the south of the Equator and over an extended austral summer wet season of October-April, which encompasses the full wet season over SA (excluding the Cape region) and those parts of EASE (south of $\sim 5^{\circ} \mathrm{S}$ ) which experience a similarly annual unimodal rainfall regime (Dunning et al., 2016), and will accommodate the response time of groundwater systems to climate. This region also experiences a coherent ENSO signal (Sect. 3.1).

We use the standardised precipitation evapotranspiration index (SPEI; Vicente-Serrano et al., 2010), which is a simple representation of surface water balance anomalies, derived over this 7-month season (SPEI-7) over the period from 1901 to present using precipitation data from the Global Precipitation Climatology Centre (GPCC) monthly product version 7 (Schneider et al., 2011, 2014) at $1.0^{\circ}$ resolution. To account for uncertainty in estimation of potential evapotranspiration (PET), we use three parameterisations of varying complexity: the Penman-Monteith equation, based on net radiation, temperature, wind speed and vapour pressure); the Hargreaves equation, based on mean, minimum and maximum temperature, and extraterrestrial solar radiation; and the Thornthwaite equation, which is based solely on surface air temperature. The variables required for the various PET estimates are obtained from the CRU TS3.24.01 dataset (Harris et al., 2014). Note that some findings will be sensitive to this choice of drought index.

SPEI-7 anomalies are analysed for two large subdomains, specifically EASE $\left(4-12^{\circ} \mathrm{S}, 30-40^{\circ} \mathrm{E}\right)$ and SA $\left(10-35^{\circ} \mathrm{S}\right.$, $10-40^{\circ} \mathrm{E}$ ), which encompass the anomalous wet and dry dipole conditions, respectively, that are typically experienced during El Niño events (Fig. S1b in the Supplement) and were specifically experienced in 2015-2016 (Fig. 1a). For each domain, the areal extent and intensity of SPEI-7 in each year of the record was characterised using intensity-areal-extentfrequency (IAF) curves of Mishra and Cherkauer (2010). IAF curves show the mean SPEI-7 value of grid cells lying within 

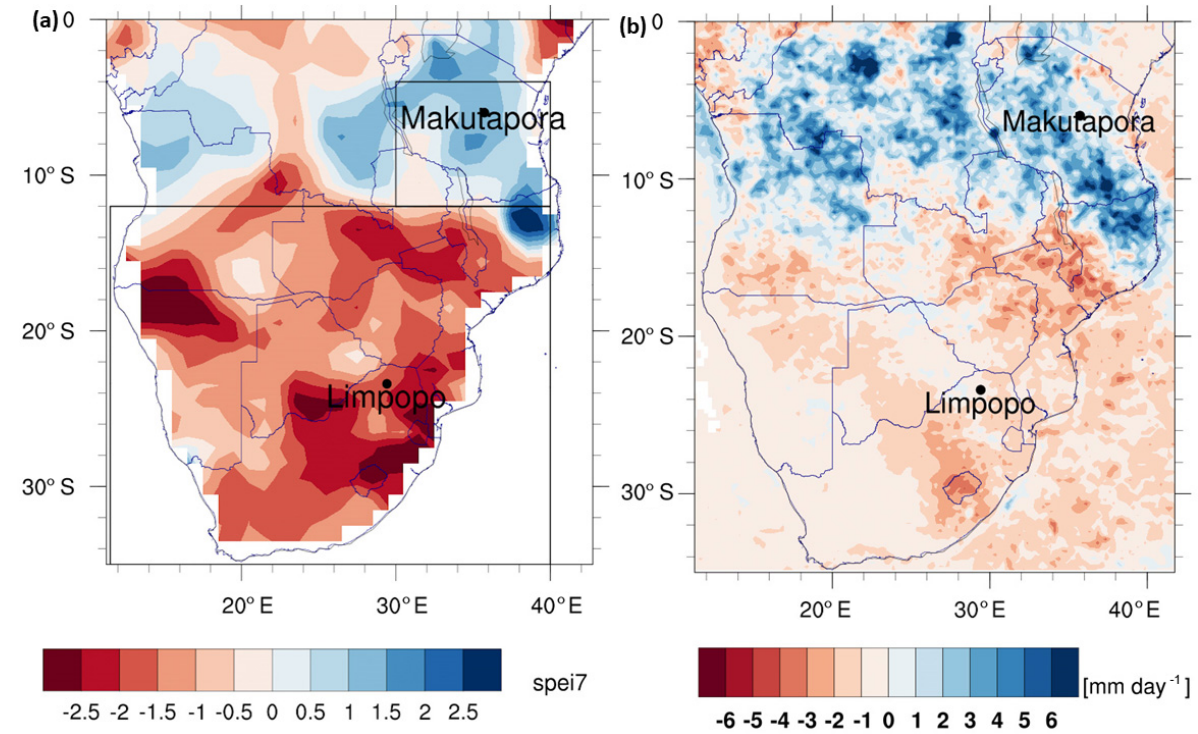

Figure 1. Large-scale climate anomalies over the study region for October-April 2015-2016. (a) SPEI-7. (b) Anomalies of the 80th percentile of daily TRMM rainfall $\left(\mathrm{mm} \mathrm{day}^{-1}\right.$ ). Boxes in (a) show the EASE (small box) and SA (large box) domains used in the SPEI-7 IAF analysis (see Sects. 2.1 and $\mathrm{S} 2$ ). The piezometer observation locations are also shown.

various areal extent intervals: the areas covered by the lowest (for SA) or highest (for EASE) 5th, 10th, 20th ... 100th areal percentiles of SPEI-7 grid cell values within the domain area, i.e. when all grid cells are ranked. The SPEI-7 IAF curves allow comparison between years, irrespective of the precise spatial location of dry and wet anomalies within the domain. This comparison includes estimating the return period of the SPEI-7 IAF curve observed during the 2015-2016 El Niño and other El Niño events. This is achieved by comparing these observed SPEI-7 IAF curves to curves representing various benchmark return periods, derived using a block maximum method applied to SPEI-7 data from a large ensemble of climate model runs (see Sect. S2).

It is likely that anthropogenic climate change is, and will continue to, affect large-scale hydrology (Bindoff et al., 2013). Here we estimate the effects purely of anthropogenic temperature trends on drought risk over SA through a simplified attribution experiment. The SPEI-7 IAF return period analysis above is repeated, but with respect to benchmark return period IAF curves for which the temperature data, used in calculating PET, have the signal of anthropogenic climate change removed (see Sect. S2). As such, the return period of the SPEI-7 IAF curve for 2015-2016 is estimated in the context of the "real historical" world and for comparison in the context of a counterfactual climate with only natural variability in temperature.

There is evidence to indicate that recharge is preferentially driven by intense rainfall (see references in Sects. 1 and 3.1.1). To examine the nature of rainfall intensities over EASE during the El Niño 2015-2016 event we derive percentiles of the daily rainfall probability distribution from the
Tropical Rainfall Monitoring Mission (TRMM) 3B42 product during the October-April season (1997-2016). In the absence of robust knowledge of actual rainfall thresholds associated with groundwater recharge, and the likelihood that such thresholds are highly variable in space and time, we derive the 80th percentile of daily rainfall within the season, at each grid cell, as a coarse proxy for rainfall events likely to be associated with recharge. Our results (Sect. 3.1.1) are largely insensitive to the choice of percentile value (not shown). We derived the value of the 80th percentile from all the October-April data and then just for the 2015-2016 season and show the anomalies. Finally, information on the largescale atmospheric circulation is diagnosed from the horizontal and vertical winds and specific humidity from ERAInterim reanalysis data (Dee et al., 2011). Sea surface temperature (SST) data are obtained from the Extended Reconstructed Sea Surface Temperature (ERSST) version 4 from the National Oceanographic and Atmospheric Administration (NOAA; Smith et al., 2008) on a $2^{\circ}$ grid.

\subsection{Groundwater storage estimates from GRACE satellite data}

Regional-scale changes in groundwater storage (GWS; 2002-2016) are estimated from GRACE satellite measurements of total terrestrial water storage (TWS) anomalies by subtracting changes in the other terrestrial stores, which, in our tropical region, comprise soil moisture (SMS) and surface water (SWS) stores (Eq. 1), estimated from land surface model (LSM) simulations, in the absence of in situ $\triangle$ SMS and $\triangle$ SWS data in the study areas: 
$\Delta \mathrm{GWS}=\Delta \mathrm{TWS}-(\Delta \mathrm{SMS}+\Delta \mathrm{SWS})$,

where $\Delta$ refers to the anomaly with respect to the longterm data series. To help with interpretation of the mean $\Delta$ GWS signals, we also present the total uncertainty in estimates of $\Delta \mathrm{GWS}$, which results from the uncertainty in estimates of $\triangle$ TWS, $\triangle$ SMS and $\Delta$ SWS. Regarding uncertainty in $\triangle$ TWS associated with different GRACE processing strategies, we apply an ensemble mean of three GRACE $\triangle$ TWS estimates, namely the CSR land (version RL05.DSTvSCS1409; Swenson and Wahr, 2006; Landerer and Swenson, 2012) and JPL Global Mascon (version RL05M_1.MSCNv01; Watkins et al., 2015; Wiese et al., 2015) solutions from NASA's GRCTellus data dissemination site (http://grace.jpl.nasa.gov/data, last access: 27 March 2019) and a third GRGS GRACE solution (CNES-GRGS release RL03-v1; Biancale et al., 2006) from the French governmental space agency, Centre National d'Études Spatiales (CNES). Further information on the processing involved in each product is provided in Sect. S3. The monthly GRACE $\triangle$ TWS data are interpolated to a $\sim 1^{\circ}$ grid for analysis in Eq. (1). For analysis of GRACE $\triangle$ TWS data at the locations of the two groundwater-level monitoring sites of interest (Makutapora and Limpopo; see below), the monthly $\triangle$ TWS time series are generated by averaging over a $200 \mathrm{~km}$ radial buffer (i.e. area equivalent of $\sim 120000 \mathrm{~km}^{2}$ ) around each location.

Further, to account for uncertainty in $\triangle \mathrm{SMS}$ and $\triangle \mathrm{SWS}$, we use data from four LSMs within NASA's Global Land Data Assimilation System (GLDAS) and provide the associated uncertainty ranges for each term. GLDAS is an uncoupled land surface modelling system that includes multiple global LSMs driven by surface meteorology from the NCEP data assimilation system, CMAP-disaggregated precipitation and the Air Force Weather Agency satellite-derived radiation fields (Rodell et al., 2004). The four GLDAS LSMs are as follows: the Community Land Model (CLM, version 2; Dai et al., 2003), NOAH (version 2.7.1; Ek et al., 2003), the Variable Infiltration Capacity (VIC) model (version 1.0; Liang et al., 2003) and MOSAIC (version 1.0; Koster and Suarez, 1992). Further discussion of the uncertainty in these individual water balance components (Fig. S2), and further information on the LSMs, is provided in Sect. S3.

\subsection{Groundwater storage estimates from piezometric observations}

Groundwater-level time series records were compiled in two areas situated at the heart of the EASE and SA ENSO rainfall dipole centres of action (Fig. 1a). (i) In the Makutapora well field $\left(35.75^{\circ} \mathrm{E}, 5.90^{\circ} \mathrm{S}\right)$ site in central Tanzania in East Africa, groundwater records were collated from the Ministry of Water and Irrigation and the Dodoma Urban Water Supply, Tanzania. Here, groundwater is abstracted from an aquifer comprising deeply weathered granite overlain by alluvium (Taylor et al., 2013). Data from three sites in the well field met the data quality criteria and are averaged together; mean groundwater-level time series records were converted to monthly anomalies in GWS using an in situ derived specific yield $\left(S_{\mathrm{y}}\right)$ value of 0.06 (Taylor et al., 2013). We estimate that these data are representative of groundwater levels across an area of $\sim 60 \mathrm{~km}^{2}$. (ii) In the Limpopo basin in Southern Africa $\left(\sim 28\right.$ to $32^{\circ} \mathrm{E}, 22.5$ to $\left.25^{\circ} \mathrm{S}\right)$, groundwater-level records from 40 stations within weathered hard-rock ("basement") aquifers in sub-basins A6 (Mogalakwena), A7 (Sand), A8 (Nzhelele) and A9 (Luvuvhu) of the Limpopo basin were collated from the Department of Water and Sanitation (Directorate: Surface and Groundwater Information), South Africa. The data were first standardised then averaged together and represent an area estimated to be $\sim 47000 \mathrm{~km}^{2}$. For both sites, daily to monthly groundwaterlevel records within our common study period from $\mathrm{Au}-$ gust 2002 to July 2016 were checked for consistency (missing data less than $10 \%$ ) and selected for groundwater storage analysis. Mean groundwater-level time series records were converted to monthly anomalies in GWS using an $S_{\mathrm{y}}$ value that produced the lowest root-mean-square error between in situ and GRACE GWS; the applied value (0.025) is consistent with that estimated for basement aquifers in Africa by MacDonald et al. (2012).

We acknowledge that our estimates of GWS from piezometry may be influenced by abstractions, and we provide data on pumping rates from Makutapora (Fig. 5c). A numerical method to remove the effects of pumping is currently the subject of ongoing research by the authors, so in this case we infer the effect of pumping on GWS only in only relative qualitative terms. Equivalent direct data on direct pumping rates are not available at Limpopo. However, we note that Cai et al. (2017) mapped the spatial extent of irrigation across the Limpopo basin in South Africa using satellite data and estimated that irrigation from groundwater provides about $50 \%$ of the irrigated areas over $2 \%$ of the land area, which likely influences groundwater storage locally.

\section{Results and discussion}

\subsection{Climate anomalies over EASE and SA during the 2015-2016 EI Niño event}

\subsubsection{EASE and SA climate anomalies}

The 2015-2016 El Niño was the second strongest event within the available $\sim 165$-year Pacific Ocean SST record, with SST anomalies exceeding $2^{\circ} \mathrm{C}$ for 6 months from October 2015 (Fig. S1d). By some measures 2015-2016 was the strongest El Niño since 1950 (Sect. S1). Many of the observed climate anomalies around the world were typical of El Niño years (Blunden and Arndt, 2016). Over our study 

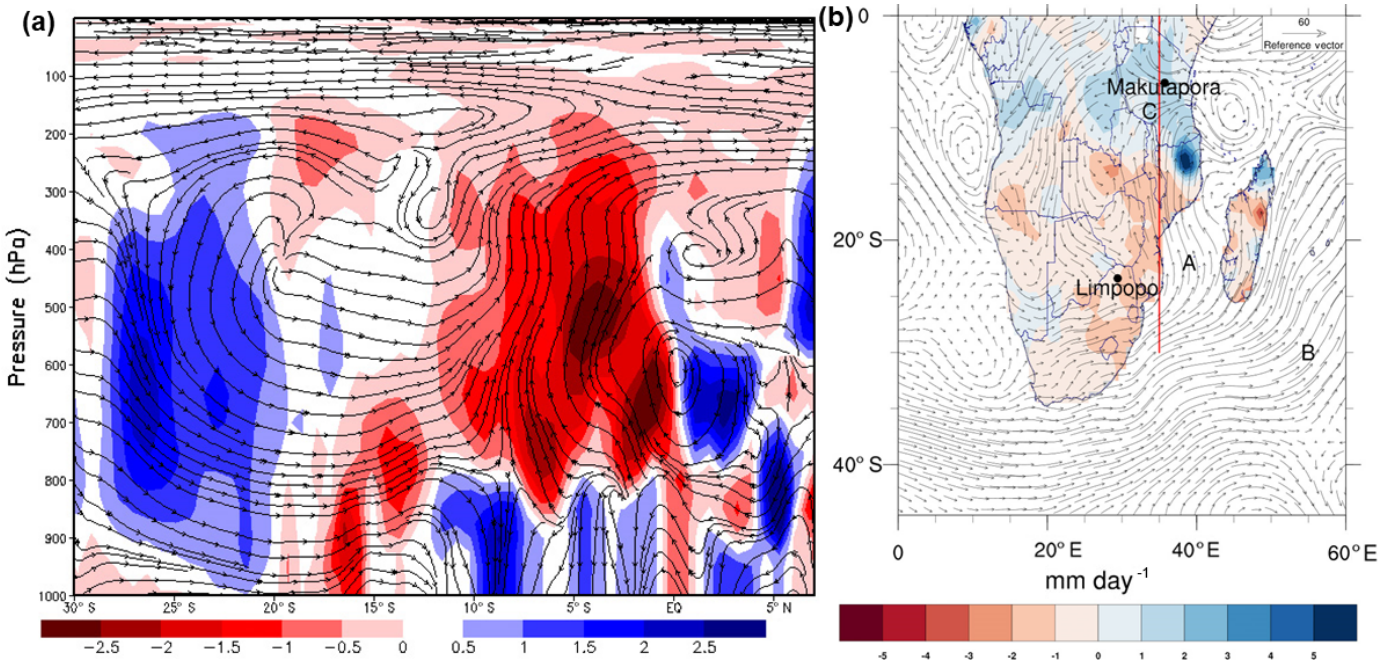

Figure 2. Circulation anomalies for October-April 2015-2016. (a) Latitude versus height transect plot of anomalous meridional overturning circulation (streamlines of vertical and meridional wind) and vertical velocity anomalies $\left(\mathrm{m} \mathrm{s}^{-1}\right.$; shaded) averaged over the $35-37^{\circ}$ E. This latitude transect is shown as a red line on the map in (b). (b) Vertically integrated moisture flux anomalies $\left(\mathrm{g} \mathrm{kg}^{-1} \mathrm{~m} \mathrm{~s}^{-2}\right.$; vectors) and rainfall anomalies $\left(\mathrm{mm} \mathrm{day}^{-1}\right.$; shaded).

region, a pronounced north-south dipole in SPEI-7 anomalies was observed (Fig. 1a), indicating intense and extensive drought over SA (negative SPEI-7) and the wetter-thannormal conditions over EASE (positive SPEI-7). In detail, most of SA south of $10^{\circ} \mathrm{S}$ experienced a substantial water balance deficit: exceptional drought (SPEI $<-2$ ) conditions were experienced over extensive parts of northern South Africa and northern Namibia, southern Botswana and Zambia, and most of Zimbabwe and southern Mozambique and Malawi (Fig. 1a). Most of EASE experienced above-average rainfall during this period, with SPEI values $>1$ across most of Tanzania and a localised exceptionally wet region over the northernmost part of Mozambique. The Makutapora and Limpopo sites (Fig. 1a) are located in areas representative of the large-scale north-south rainfall dipole.

This spatial dipole pattern is very similar to the characteristic pattern of anomalies during El Niño across the region, as represented by the leading empirical orthogonal function (EOF) of inter-annual variability (Fig. S1b; Sect. S1), which correlates strongly with ENSO and Indian Ocean SSTs (Fig. S1c). Indeed, the EOF coefficient value for 2015-2016 is the second highest within the entire 1901-2016 period. As such, across our study region, 2015-2016 represents an extreme exemplar of the characteristic El Niño climate response. Of course, a complex set of processes on the planetary, regional and local scale related to, and independent of, El Niño are fully responsible for the observed anomalies (e.g. Blamey et al., 2018). The structure of the atmospheric anomalies, specifically the mean meridional overturning circulation associated with the large-scale SPEI-7 anomalies (Fig. 2a), shows large-scale anomalous ascent over EASE between $\sim 0$ and $10^{\circ} \mathrm{S}$, indicative of enhanced deep con- vection, with compensating descent over SA throughout the depth of the troposphere, which acts to suppress convection. The low-level horizontal circulation (Fig. 2b) indicates key features associated with the SPEI-7 dipole, notably (i) an anomalous southerly flow from the southern Indian Ocean into continental SA (feature A in Fig. 2b), which weakens the transport of water vapour from the humid tropical Indian Ocean, leading to a decrease in moisture flux convergence over SA. This is associated with a weakening of the mean "Mascarene" subtropical high over the Southern Indian Ocean (feature B in Fig. 2b). (ii) Over EASE there are anomalous low-level westerlies over Tanzania (feature $\mathrm{C}$ in Fig. 2b), which weaken the mean easterlies and enhance convergence over Tanzania, a structural characteristic of wet spells (Berhane and Zaitchik, 2014; Nicholson, 2017).

Groundwater recharge in the semi-arid tropics is favoured by high-intensity rainfall events (Owor et al., 2009; Jasechko and Taylor, 2015) within wet seasons, which may be modulated by climate anomalies during El Niño conditions. During 2015-2016, the intensities of the 80th percentile of daily rainfall, a simple proxy of potential groundwater-rechargerelevant rainfall, increased by $\sim 1-5 \mathrm{~mm} \mathrm{day}^{-1}$ across much of EASE (Fig. 1b), representing a 100\%-150\% increase in many places. Whilst the association of rainfall intensity and enhanced recharge across large and heterogeneous regions remains to be resolved, this intensification of rainfall is consistent with greater groundwater recharge. Across SA the magnitude of the 80th percentile reduced by $\sim 1-$ $2 \mathrm{~mm} \mathrm{day}^{-1}$, potentially reducing groundwater recharge. 


\subsubsection{The 2015-2016 event in the historical context}

SPEI-7 IAF curves represent water balance anomalies across all spatial scales. For the SA region, 2015-2016 experienced the most extreme SPEI-7 drought within the historical period, with an estimated IAF curve return period of $\sim 260$ years (range 190-290 years; Fig. 3a). The 20152016 drought was of greater intensity than those during previous El Niño events of comparable magnitude, 19971998 and 1982-1983, whose SPEI-7 IAF curve return periods are estimated to be only $\sim 6$ years (range $4-9$ years) and $\sim 43$ years (range 35-47 years), respectively. The contrasting intensity of SA drought between these events highlights the diversity in responses over EASE and SA to El Niño, related to both the different character of the events in the Pacific sector (2015-2016 was strongest in the central rather than eastern Pacific as in 1997-1998; see Sect. S1) and the specific regional circulation features during these events which modulate the diverse ENSO teleconnections to SA (Ratnam et al., 2014; Blamey et al., 2018). Moreover, the 2015-2016 drought followed a moderate drought in 2014-2015 (Blamey et al., 2018), which had important implications for groundwater levels (Sect. 3.2.2), and statistically this 2-year drought event is remarkably unlikely. The extreme SPEI-7 anomalies over SA in 2015-2016 result from low rainfall and extremely high temperatures (Blunden and Arndt, 2016; Russo et al., 2016), potentially related to land-atmosphere feedback processes (e.g. Seneviratne et al., 2010), through reduced vegetation and soil moisture, perhaps persisting from 2014-2015. Uncertainty in the strength of land-atmosphere coupling over SA remains high with contradictory results from model analyses (e.g. Koster et al., 2006) and combined observation-model analysis (Ferguson et al., 2012), suggesting weak and strong coupling, respectively. Further, warming across SA in recent decades can be attributed substantially to anthropogenic radiative forcing (Bindoff et al., 2013). As such climate risks are changing. We estimate that the risk of a 2015-2016 magnitude SPEI-7 drought over SA increased by approximately 2 times due to the effects purely of anthropogenic warming. Note that this estimate does not include any anthropogenic changes in any of the other climate variables which determine SPEI, most notably precipitation, nor changes in variability of climate (see Sect. S2). Further, other drought indices may have differing sensitivities to anthropogenic temperature trends.

Over the EASE domain as a whole, the 2015-2016 event was wet but not extreme, with an return period estimated by the SPEI-7 IAF curve (Fig. 3b) of only $\sim 10$ years (range: 5-12 years). The anomalies were far weaker than those during the 1997-1998 El Niño (Fig. 3b). These differences may be associated with the state of the Indian Ocean zonal model (IOZM), an east-west structure of coupled ocean-atmosphere circulation, influencing convection and rainfall over East Africa (Saji et al., 1999, Sect. S1). The 1997-1998 El Niño coincided with a very strong pos-

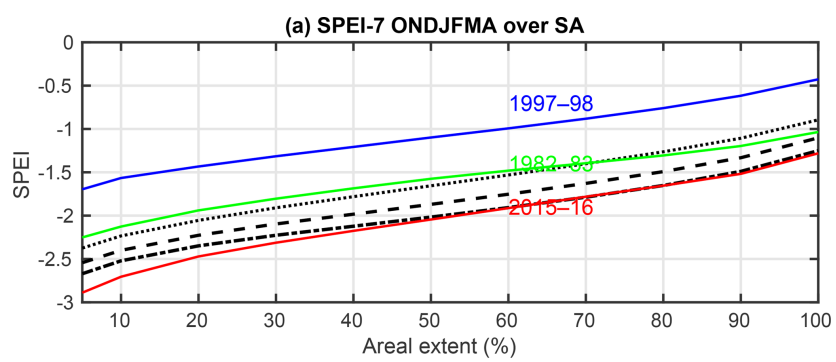

(b) SPEI-7 ONDJFMA over EASE

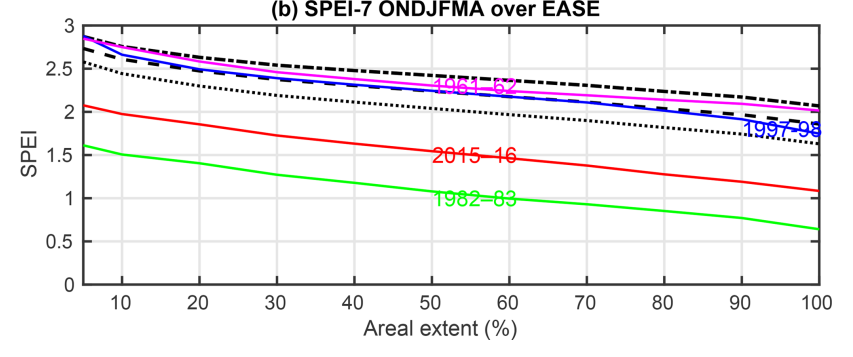

Figure 3. Intensity-areal-extent-frequency (IAF) curves (see Sects. 2.1 and S2 for details of method) estimated from the seasonal mean SPEI-7 (derived with Penman-Monteith PET; see text for uncertainty ranges) over (a) the Southern Africa domain (10.5$35.5^{\circ} \mathrm{S}$; see box in Fig. 1a) and (b) the East Africa domain (30$40^{\circ} \mathrm{E}, 4-12^{\circ} \mathrm{S}$; see box in Fig. 1a). On the $x$ axis is the areal extent over which the SPEI is averaged, and on the y axis is the SPEI7 drought intensity. Solid coloured lines show the IAF curves for the study El Niño event years: 2015-2016 (red), 1997-1998 (blue), 1982-1983 (green) and (in b only) the 1961-1962 Indian Ocean zonal mode event (purple). Black lines are the IAF curves for selected benchmark return periods (from top to bottom in a and bottom to top in b): 50 years (dotted), 100 years (dashed) and 200 years (dotted-dashed).

itive IOZM event, unlike that of 2015-2016, in which the IOZM was weakly positive. Indeed, the wettest EASE year on record, 1961-1962, experienced a very strongly positive IOZM event but no El Niño event (Nicholson, 2015).

\subsection{Impact of 2015-2016 climate anomalies on groundwater storage}

\subsubsection{Large-scale estimates of $\Delta \mathrm{TWS}, \Delta \mathrm{SMS}, \Delta \mathrm{SWS}$ and $\Delta$ GWS}

Regionally, GRACE ensemble-mean $\triangle$ TWS anomalies (Fig. 4a), and estimated $\triangle$ GWS (Eq. 1; Fig. 4d), for 20152016 reflect the north-south dipole over EASE and SA associated with the SPEI-7 climate anomalies related to El Niño (Fig. 1a). Positive $\triangle$ TWS and $\triangle$ GWS anomalies exist north of $\sim 10^{\circ} \mathrm{S}$ across EASE (including the Makutapora site), the central Democratic Republic of the Congo (DRC) and northern Angola. Negative $\triangle$ TWS and $\triangle$ GWS anomalies occur over an extensive region of eastern SA including the Limpopo site. However, despite broad-scale structural similarity, there are some apparent inconsistencies between $\Delta$ TWS (and other components of the water budget, includ- 
(a) GRACE TWS: ONDJFMA [2015-16]

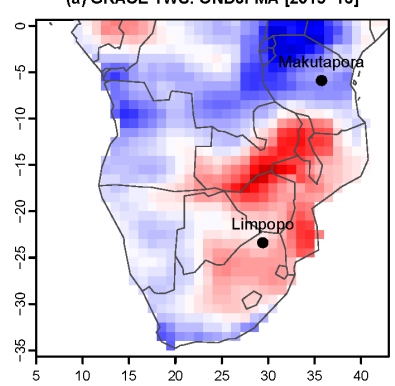

(c) GLDAS SWS: ONDJFMA [2015-16]
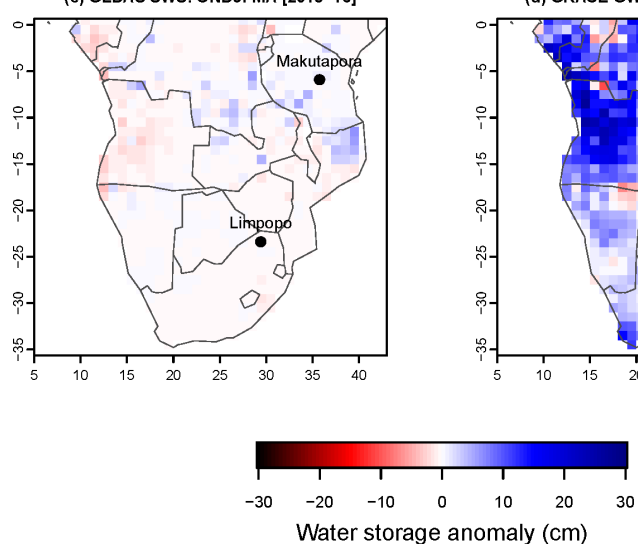

Figure 4. Water storage anomaly components $(\mathrm{cm})$ over the study domain for the wet season (October-April) of 2015-2016 minus long-term annual mean from 2003-2015. (a) GRACE ensemblemean total water storage anomaly ( $\triangle \mathrm{TWS}$; from CSR, JPL Mascons and GRGS GRACE products). (b) GLDAS ensemble-mean soil moisture storage anomaly ( $\triangle \mathrm{SMS}$; four land surface models: CLM, NOAH, VIC and MOSAIC). (c) GLDAS ensemblemean surface runoff or surface water storage anomaly $(\triangle \mathrm{SWS}$; from four land surface models: CLM, NOAH, VIC and MOSAIC), and (d) GRACE-GLDAS-derived ensemble-mean groundwater storage anomaly ( $\triangle \mathrm{GWS}$; from three estimates of $\triangle \mathrm{GWS}$ from three GRACE products).

ing $\triangle$ GWS) and the SPEI-7 climate signal that we consider below.

Viewed more closely, the partitioning of large-scale $\Delta$ TWS anomalies between the modelled $\Delta$ SMS, $\Delta$ SWS and residual $\Delta$ GWS is spatially complex. First, we note that $\Delta$ SWS (Fig. 4c) plays only a minor role across the domain. Further, the coherence of the spatial structure in anomalies in $\triangle$ SMS (Fig. 4b) is much less clear than for $\Delta$ TWS, reflecting uncertainties in soil moisture among individual LSMs, as highlighted by Scanlon et al. (2018). Then, considering the drought region over SA, a number of features emerge. (i) The relative magnitude of $\triangle$ TWS deficits over South Africa are less than those of the SPEI-7, compared to the northern more humid parts of SA (compare Figs. 4a and 1a). This difference may be expected, since $\triangle$ TWS is an absolute measure of water volume, whereas SPEI-7 is a standardised anomaly relative to climate, derived over a much longer time period from different rainfall data than those used in the GLDAS system. Consequently, these measures may be expected to diverge across mean rainfall gradients. Further, SPEI-7 reflects potential rather than actual evapotranspiration. (ii) Over the northern sector of Zambia, Zimbabwe and Malawi, the strongly negative $\Delta$ TWS anomaly is almost equally shared between modelled reductions in $\triangle \mathrm{SMS}$ and $\Delta$ GWS. (iii) To the south, over South Africa, however, the (rather weaker) $\Delta$ TWS deficits are effectively accounted for by $\triangle$ SMS anomalies such that $\Delta \mathrm{GWS}$ anomalies are actually close to zero or indeed slightly positive. The Limpopo study site lies at a transition zone between regions with apparently strongly reduced $\Delta \mathrm{GWS}$ to the northeast and close to zero or slightly positive $\Delta$ GWS to the southwest. As geology is broadly continuous across the region, the transition is largely related to uncertainty in the estimation of modelled $\triangle$ SMS.

Further, considering the anomalous wet region over EASE to the north of $\sim 10^{\circ} \mathrm{S}, \Delta \mathrm{GWS}$ broadly mirrors the structure of $\Delta$ TWS, but the detailed picture is complex. Over most of Tanzania and Angola, positive $\Delta$ TWS anomalies are largely partitioned into the $\Delta \mathrm{GWS}$ rather than $\triangle \mathrm{SMS}$, whereas over the southern DRC, the reverse is the case. Moreover, there are interesting apparent contradictions between the climate SPEI-7 and GRACE $\triangle$ TWS data. Over Namibia and southern Angola, a negative SPEI-7 (Fig. 1a and $\triangle$ SMS; Fig. 4b) coincides with positive $\Delta$ TWS anomalies (Fig. 4a), leading to very strong positive $\Delta$ GWS anomalies (Fig. 4d) that are therefore inconsistent with climate anomalies from SPEI-7. Conversely, and more locally, over northern Mozambique, a positive $\triangle \mathrm{SMS}$ anomaly, resulting from the driving rainfall data (see the SPEI-7 wet anomaly; Fig. 1a) is not reflected in a strong $\Delta$ TWS signal, which leaves a counter-intuitive, negative residual response in $\triangle$ GWS. As such, GRACE $\Delta$ GWS exhibits inconsistent responses to both apparent anomalous dry and wet conditions. These are likely to be a result of (i) limitations in observational precipitation data, (ii) uncertainties in GRACE TWS retrievals (as well as unwanted artefacts from surface and tectonic deformation), (iii) uncertainties in estimation of the individual components of water storage from LSMs and (iv) differing timescales of response across the various data. Such issues have been noted and assessed elsewhere (Hassan and Jin, 2016; Zhao et al., 2017; Rodell et al., 2018; Scanlon et al., 2018). Resolving these issues is challenging, but recent studies have sought to constrain the uncertainty in the modelled components of water storage through assimilation of GRACE TWS into hydrological models (Khaki et al., 2018; Schumacher et al., 2018).

\subsubsection{In situ and GRACE-derived estimates of $\Delta$ GWS at the Makutapora and Limpopo basins}

Piezometry for the two observatory sites and changes in GWS estimated from GRACE and LSMs are shown in Fig. 5. First, we note that uncertainty in the mean GRACE $\triangle$ GWS estimate (blue shading around blue line in Fig. 5a and b), 

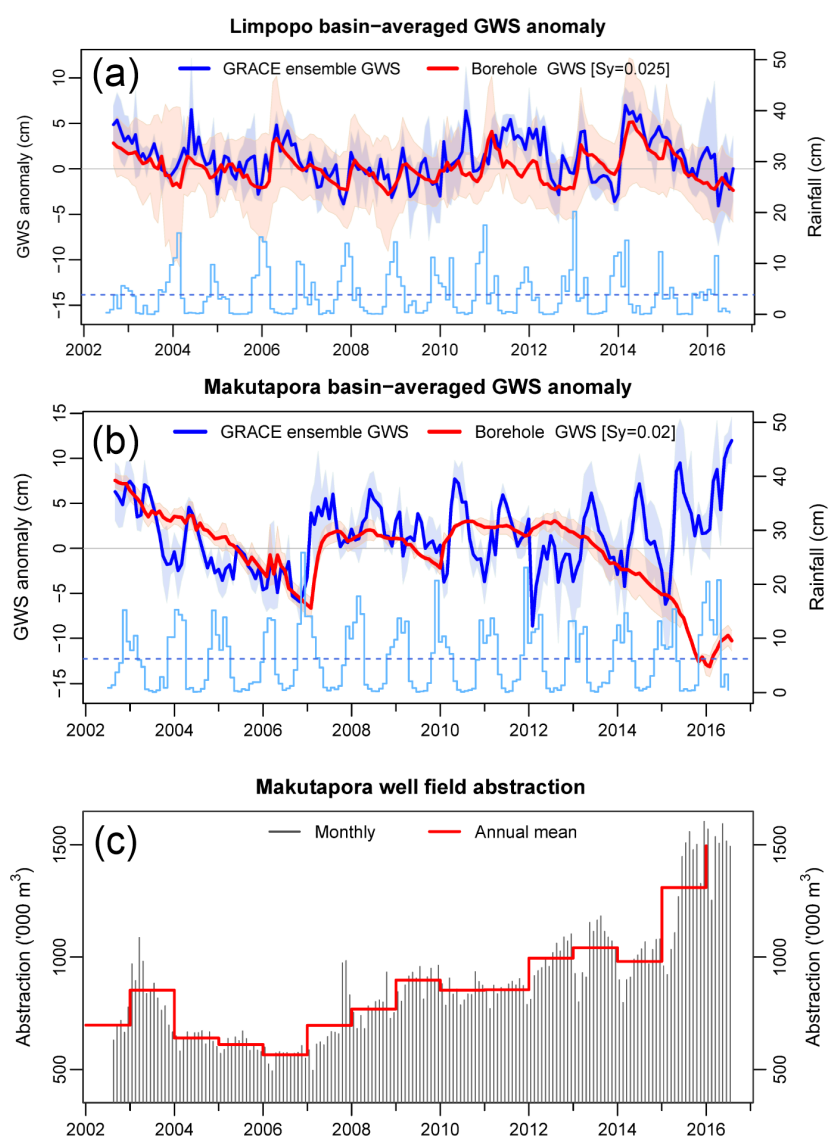

Figure 5. (a) Time series of estimates of monthly $\Delta$ GWS anomaly (cm) at Limpopo from August 2002 to July 2016 derived from GRACE and averaged over an area of approximately $120000 \mathrm{~km}^{2}$ (bold blue line is the mean of CSR, JPL Mascons and GRGS products; light blue shading represents uncertainty across the three products and four LSMs) and piezometry (red line, mean of all stations; red shading represents uncertainty). Monthly rainfall (from GPCP product; $\mathrm{cm}$ ) shown as bars, with mean monthly rainfall indicated by a dashed line; (b) as in (a), but for Makutapora. (c) Monthly groundwater abstraction at Makutapora.

whilst often large, is generally smaller than the signals of inter-annual variability which are the main focus of our analysis. However, variability in mean GRACE $\triangle$ GWS within recharge seasons is small relative to uncertainty, such that we cannot confidently draw inferences at these timescales.

Specifically, at the SA Limpopo site, observed piezometry (Fig. 5a) shows an annual cycle in GWS in most years, with a "sawtooth" pattern representing steady recessions in GWS during the dry season from May to October followed by rapid increases typically starting in December in response to the onset of the wet season to the peak post wet season in April (lagging peak rainfall by $\sim 1-2$ months). GWS in 2015-2016 is well below average, with a seasonal but subdued GWS rise being delayed (until March) due to the highly anomalous early wet season drought. The GWS rise in March-April following rains in March is the second smallest on record; only $2002-2003$ has a lower seasonal increase in GWS. The 2015-2016 drought is preceded by negligible recharge in the dry year of 2014-2015 (Fig. 5a) such that GWS as of mid2016 was lowest in the 14-year record. As such, the major drought of 2015-2016 compounded weak recharge in the previous year, leaving GWS at historically low levels. This may have been compounded by increased abstractions during these dry years.

Comparison of piezometry and GRACE-derived GWS at Limpopo (Fig. 5a) suggests a broad correspondence when seasonally averaged, $(r=0.62$, significant at the 0.01 probability level). The prolonged decline over 2014-2016 is observed in both GRACE and piezometry. When averaged over all years, the mean annual cycle is similar in phase and magnitude (not shown). As such, at least for broad temporal averaging scales, GRACE is corroborated by piezometry at the Limpopo site, where the scales of spatial averaging are similar. However, within seasons, the uncertainty in GRACE $\triangle$ GWS leads to a much "noisier" mean signal at Limpopo which cannot resolve the annual sawtooth pattern (Fig. 5a); in GRACE $\triangle$ GWS, individual years have a rather variable annual cycle despite a clear cycle in rainfall. Notably, a strong rise in the ensemble-mean GRACE $\triangle$ GWS during early season 2015-2016 is not corroborated by piezometry or rainfall. This period coincides with the greatest uncertainty in GRACE $\triangle$ GWS among the three GRACE products (see blue shading around ensemble-mean GRACE estimates in Fig. 5a). There is some indication from Fig. S2 that during such periods of greatest $\Delta$ GWS uncertainty, it is the uncertainty in GRACE $\triangle$ TWS that makes most important contribution, rather than uncertainty in the GLDAS components. From the individual GRACE $\triangle$ TWS products (Fig. S3) we note that the mean GRACE vs. piezometry $\triangle$ GWS discrepancies in late 2015 result largely from the GRGS product, which shows a non-corroborated increase in $\triangle$ TWS.

At the EASE Makutapora site, observed piezometric GWS (Fig. 5b) shows little regular inter-annual variability, with long periods of GWS recessions, e.g. 2002-2006 and 20122016, interrupted by irregular and infrequent GWS increases, which are, in declining order of magnitude, 20062007, 2009-2010 and 2015-2016, all El Niño years. The wet conditions in 2015-2016 produced a major recharge event, though observed piezometric responses are smaller than in 2006-2007 and 2009-2010, despite higher rainfall (Fig. 5b). Under highly dynamic pumping regimes (Fig. 5c), GWS changes are only a partial proxy for groundwater recharge; the sharp increase $(\sim 50 \%)$ in well field pumping in May 2015 served to diminish the response in piezometric GWS to the 2015-2016 El Niño. Overall, however, the findings are consistent with the analysis of Taylor et al. (2013), who note highly episodic recharge at Makutapora over the period since the 1960 s, associated with years of heavy rainfall. The 2015-2016 El Niño event represents a major event driving GWS at the Makutapora well field, despite moderate rainfall anomalies over EASE. 
There is only a rather general association between GRACE and piezometric estimates of groundwater storage variability at the Makutapora site. However, the episodic recharge events in the piezometry data of 2006-2007, 2009-2010 and 2015-2016 are matched quite well by the magnitude of major GRACE increases in $\triangle \mathrm{GWS}$, although the second largest GRACE $\triangle$ GWS increase occurs in 2014-2015 with no response apparent in piezometry. Overall, the seasonal correlation of GRACE $\triangle \mathrm{GWS}$ and piezometric GWS of 0.51 is only moderate (significant at the 0.05 probability level) but clearly reflects the low-frequency multi-annual trends (at least up to 2013) as well as inter-annual variability.

However, stark differences between GRACE and piezometry are apparent. In contrast to piezometry, GRACE (Fig. 5b) shows increases in $\triangle \mathrm{GWS}$ in most years (with lag of $~$ 1 month after the rainfall annual peak), suggesting that recharge occurs annually. Further, GRACE $\triangle$ GWS replicates the low-frequency recessionary trend over the period 20022007 but diverges substantially from piezometric observations after 2012. Resolving these contradictions is problematic, but two likely explanations emerge: (i) incommensurate scales of observation from piezometry (area $\sim 60 \mathrm{~km}^{2}$ ) and GRACE $\left(\sim 200000 \mathrm{~km}^{2}\right)$ and (ii) errors in GRACE $\Delta$ GWS resulting from inaccurate accounting of $\triangle \mathrm{SMS}$ and $\triangle \mathrm{SWS}$, which leave a residual artefact of an annual positive $\Delta$ GWS signal (see Sect. 3.1; Shamsudduha et al., 2017, and Scanlon et al., 2018). For the latter, such errors may not be adequately accounted for in the uncertainty estimates in GRACE $\triangle$ GWS given, for example, similarities in LSM design and driving data. Indeed, at both the Limpopo and Makutapora sites, we note stronger correlations between seasonal local rainfall and piezometric GWS than with GRACE $\triangle$ GWS (not shown). For the former, more localised processes may dominate the piezometry record, perhaps including recharge sensitivity to contributions from local ephemeral river flow and rainfall. Further, the effects of local pumping strongly influence the piezometric record, obscuring recharge events of low magnitude. Specifically, the period 2002-2007 over which the data agree reflects a widespread groundwater recession, following the anomalously high recharge during the El Niño event of 1997-1998 (Taylor et al., 2013), whilst the recent accelerated recessionary trend since 2012 reflects the effects of a rapid increase in abstraction, which has a more localised effect apparent only in the piezometric observations. As such the piezometric record may only show episodic recharge, whilst GRACE may indicate annual and episodic recharge processes.

\section{Concluding discussion}

We quantify the climate anomalies and groundwater response during the major El Niño event of 2015-2016 over Southern and East Africa, south of the Equator, across a range of spatial scales, from regional to local. Our analysis confirms that the event was associated with a pronounced north-south dipole pattern of positive or negative rainfall and water balance anomalies over EASE and SA, typical of the ENSO teleconnection to the region. It was the second largest such dipole event on record since 1900. Considerable diversity nevertheless exists in climate anomalies over Africa between El Niño events.

The response of the water balance including GWS to ENSO is marked. Over EASE, total rainfall and daily intensities were higher than normal, and we estimate the return period for the SPEI-7 water balance metric, over the domain as a whole, to be $\sim 10$ years. Wet anomalies over EASE were actually moderated by the occurrence of a rather weak IOZM event. Nevertheless, the anomalously wet conditions led to strong groundwater recharge over the EASE domain, as evidenced from GRACE. At the Makutapora well field in Tanzania, in 2015-2016 the strong rainfall related to El Niño acted to reverse a long-term decline in observed in situ groundwater storage associated with a rise in intensive pumping rates. Changes in GWS estimated from an ensemble of GRACE and LSMs also reflect the occurrence of substantial groundwater recharge in 2015-2016 and indicate annual groundwater recharge across the region. Broadly, the analysis reinforces the importance of large-scale climate events in driving episodic recharge, critical in replenishing heavily exploited aquifers.

Over SA, the 2015-2016 El Niño was associated with extreme drought, the strongest within the observed 116-year record, with an estimated return period of $\sim 260$ years, resulting from exceptionally low rainfall and high temperatures. The drought resulted in groundwater storage declines through most of the wet season at our Limpopo study site, with strongly reduced recharge experienced, the second lowest on record. Furthermore, this followed a dry year in 20142015 , leading to 2 consecutive years of low recharge and the greatest recession on record. Clearly, groundwater provides a valuable buffer for periods of reduced surface water availability in drought conditions, although as our results at Limpopo show, consecutive dry years lead to marked storage reduction. Climate projections suggest reduced early season rainfall across much of SA (Lazenby et al., 2018) compounding rising temperatures, and the implications of this for climate resilience require a better understanding of these impacts on groundwater recharge as well as surface water resources.

GRACE data and LSM outputs are clearly useful in complementing in situ data, but a number of issues emerge. Although at the broadest scale the GRACE $\triangle$ GWS anomalies in 2015-2016 are consistent with rainfall anomalies, there are a number of apparent inconsistencies over quite large areas. Resolving the underlying reasons for these is problematic, but likely candidates include the effects of inadequate climate data over Southern Africa, influencing and compounded by uncertainties in $\triangle$ SMS and $\triangle$ SWS estimates simulated by land surface models on which the estimation 
of GRACE $\triangle$ GWS depends. When averaged over comparable scales at Limpopo, GRACE and piezometry agree well, at least for seasonal averages. Comparison with the local observations shows that GRACE GWS estimates are considerably noisier, especially at Makutapora, where the spatial averaging scale of in situ data and GRACE differ greatly. Local groundwater abstractions are apparent in the Makutapora record and very likely at Limpopo. Our results suggest that further analysis of the robustness of GRACE estimates of GWS is advisable and, as such, that these estimates should be treated with considerable caution.

Our results highlight the potential for adaptive strategies, such as managed aquifer recharge, for optimising the capture or storage of episodic recharge in East Africa during El Niño and/or positive IOZM events and by corollary over Southern Africa during La Niña events (given the opposing dipole structure of ENSO-related rainfall anomalies across SA/EASE). Of course other modes of climate variability driving rainfall extremes are also important. Such interventions can enhance the positive role of groundwater in climateresilient water and drought management. Seasonal climate prediction may have a potential role in informing such adaptive water management strategies. At Makutapora, managed aquifer recharge exploiting El Niño and/or positive IOZM events may contribute to resilient urban water supply systems for the city of Dodoma. Our findings strengthen the case for a greater understanding of the drivers of rainfall extremes over Africa and their relationship with recharge processes under past, current and future climates and at various temporal and spatial scales. Such knowledge is crucial in informing water management policies and practices for sustainable and climate resilient development in a region undergoing rapid development of groundwater resources.

Data availability. Data are available from the corresponding author on request.

Supplement. The supplement related to this article is available online at: https://doi.org/10.5194/hess-23-1751-2019-supplement.

Author contributions. SRK and MCT conceived the paper. Data analysis was conducted by all authors. MCT and SRK prepared the paper with contributions from all co-authors.

Competing interests. The authors declare that they have no conflict of interest.

Acknowledgements. This project was supported by the following research grant awards, funded by the UK Natural Environment Research Council (NERC) and Economic and Social Research Council (ESRC) and the UK Department for International Devel- opment (DfID): (i) the Unlocking the Potential of Groundwater for Poverty Alleviation (UpGro) consortium project "GroFutures" (grant numbers NE/M008207/1 and NE/M008932/1; see http:// grofutures.org/, last access: 27 March 2019), (ii) the Future Climate For Africa (FCFA) consortium project "UMFULA" (grant number NE/M020258; see http://www.futureclimateafrica.org/, last access: 27 March 2019), and (iii) the Science for Humanitarian Emergencies And Resilience (SHEAR) consortium project "ForPAc" (grant number NE/P000673/1 and NE/P000568/1; see https://www. forpac.org/, last access: 27 March 2019). Further contribution was received from the UK Engineering and Physical Sciences Research Council (EPSRC) "Banking the Rain", grant number 172313, under the Global Challenges Research Fund (GCRF), and the Royal Society Leverhulme Senior Fellowship to Richard G. Taylor (reference LT170004). Mark O. Cuthbert is supported by a UK NERC Independent Research Fellowship (grant number NE/P017819/1). The Chronicles Consortium (https://www.un-igrac.org/special-project/ chronicles-consortium, last access: 27 March 2019), which coordinates long-term groundwater in situ observations, was supported by the UK government under the UPGro programme. This research used science gateway resources of the National Energy Research Scientific Computing Center, a DOE Office of Science user facility supported by the Office of Science of the US Department of Energy under contract no. DE-AC02-05CH11231. The authors would like to thank the editor and reviewers for their constructive comments and suggestions which led to substantial improvements in the paper.

Review statement. This paper was edited by Shraddhanand Shukla and reviewed by three anonymous referees.

\section{References}

Archer, E. R. M., Landman, W. A., Tadross, M. A., Malherbe, J., Weepener, H., Maluleke, P., and Marumbwa, F. M.: Understanding the evolution of the 2014-2016 summer rainfall seasons in southern Africa: Key lessons, Clim. Risk Manage., 16, 22-28, 2017.

Berhane, F. and Zaitchik, B: Modulation of daily precipitation over East Africa by the Madden-Julian oscillation, J. Climate, 27, 6016-6034, 2014.

Biancale, R., Lemoine, J.-M., Balmino, G., Loyer, S., Bruisma, S., Perosanz, F., Marty, J.-C., and Gégout, P.: 3 Years of Geoid Variations from GRACE and LAGEOS Data at 10-day Intervals from July 2002 to March 2005, CNES/GRGS product data available on CD-ROM, 2006.

Bindoff, N. L., Stott, P. A., AchutaRao, K. M., Allen, M. R., Gillett, N., Gutzler, D., Hansingo, K., Hegerl, G., Hu, Y., Jain, S., Mokhov, I. I., Overland, J., Perlwitz, J., Sebbari, R., and Zhang, X.: Detection and Attribution of Climate Change: from Global to Regional, in: Climate Change 2013: The Physical Science Basis, Contribution of Working Group I to the Fifth Assessment Report of the Intergovernmental Panel on Climate Change, edited by: Stocker, T. F., Qin, D., Plattner, G.-K., Tignor, M., Allen, S. K., Boschung, J., Nauels, A., Xia, Y., Bex, V., and Midgley, P. M., Cambridge University Press, Cambridge, UK and New York, NY, USA, 2013. 
Blamey, R. C., Kolusu, S. R., Mahlalela, P., Todd, M. C., and Reason, C. J. C.: The role of regional circulation features in regulating El Niño climate impacts over southern Africa: A comparison of the 2015/2016 drought with previous events, Int. J. Climatol., 38, 4276-4295, https://doi.org/10.1002/joc.5668, 2018.

Blunden, J. and Arndt, D. S. : State of the Climate in 2016, B. Am. Meteorol. Soc., 98, Si-S280, 2016.

Bonsor, H., Shamsudduha, M., Marchant, B., MacDonald, A., and Taylor, R: Seasonal and decadal groundwater changes in African sedimentary aquifers estimated using GRACE products and LSMs, Remote Sens., 10, 904, https://doi.org/10.3390/rs10060904, 2018.

Cai, X., Magidi, J., Nhamo, L., and van Koppen, B.: Mapping irrigated areas in the Limpopo Province, South Africa, IWMI Working Paper 172, International Water Management Institute (IWMI), Colombo, Sri Lanka, p. 37, https://doi.org/10.5337/2017.205, 2017

Calow, R. C., MacDonald, A. M., Nicol, A. L., and Robins, N. S.: Ground water security and drought in Africa: linking availability, access, and demand, Groundwater, 48, 246-256, 2010.

Cuthbert, M. O., Acworth, R. I., Andersen, M. S., Larsen, J. R., McCallum, A. M., Rau, G. C., and Tellam, J. H.: Understanding and quantifying focused, indirect groundwater recharge from ephemeral streams using water table fluctuations, Water Resour. Res., 52, 827-840, https://doi.org/10.1002/2015WR017503, 2016.

Cuthbert, M. O., Gleeson, T., Reynolds, S. C., Bennett, M. R., Newton, A. C., McCormack, C. J., and Ashley, G. M.: Modelling the role of groundwater hydro-refugia in East African hominin evolution and dispersal, Nat. Commun., 8, 15696, https://doi.org/10.1038/ncomms15696, 2017.

Dai, Y., Zeng, X., Dickinson, R. E., Baker, I., Bonan, G. B., Bosilovich, M. G., Denning, A. S., Dirmeyer, P. A., Houser, P. R., Niu, G., and Oleson, K. W., and Oleson, K. W.: The common land model, B. Am. Meteorol. Soc., 84, 1013-1024, 2003.

Dee, D. P., Uppala, S. M., Simmons, A. J., Berrisford, P., Poli, P., Kobayashi, S., Andrae, U., Balmaseda, M. A., Balsamo, G., Bauer, D. P., and Bechtold, P.: The ERA-Interim reanalysis: Configuration and performance of the data assimilation system, Q. J. Roy. Meteorol. Soc., 137, 553-597, 2011.

Dunning, C. M., Black, E. C., and Allan, R. P.: The onset and cessation of seasonal rainfall over Africa, J. Geophys. Res.-Atmos., 121, 11-405, 2016.

Ek, M. B., Mitchell, K. E., Lin, Y., Rogers, E., Grunmann, P., Koren, V., Gayno, G., and Tarpley, J. D.: Implementation of Noah land surface model advances in the National Centers for Environmental Prediction operational mesoscale Eta model, J. Geophys. Res.-Atmos., 108, 8851, https://doi.org/10.1029/2002JD003296, 2003.

Ferguson, C. R., Wood, E. F., and Vinukollu, R. K.: A global intercomparison of modeled and observed land-atmosphere coupling, J. Hydrometeorol., 13, 749-784, 2012.

Harris, I. P. D. J., Jones, P. D., Osborn, T. J., and Lister, D. H.: Updated high-resolution grids of monthly climatic observations - the CRU TS3.10 Dataset, Int. J. Climatol., 34, 623-642, 2014.

Hassan, A. and Jin, S.: Water storage changes and balances in Africa observed by GRACE and hydrologic models, Geod. Geodynam., 7, 39-49, https://doi.org/10.1016/j.geog.2016.03.002, 2016.
Holman, I. P., Rivas-Casado, M., Bloomfield, J. P., and Gurdak, J. J.: Identifying non-stationary groundwater level response to North Atlantic ocean-atmosphere teleconnection patterns using wavelet coherence, Hydrogeol. J., 19, 1269, https://doi.org/10.1007/s10040-011-0755-9, 2011.

Hunter, P. R., MacDonald, A. M., and Carter, R. C. : Water supply and health, PLoS Medicine, 7, e1000361, https://doi.org/10.1371/journal.pmed.1000361, 2010.

Jasechko, S. and Taylor, R. G. : Intensive rainfall recharges tropical groundwaters, Environ. Res. Lett., 10, 124015, https://doi.org/10.1088/1748-9326/10/12/124015, 2015.

Khaki, M., Forootan, E., Kuhn, M., Awange, J., van Dijk, A. I. J. M., Schumacher, M., and Sharifi, M. A.: Determining Water Storage Depletion within Iran by Assimilating GRACE data into the W3RA Hydrological Model, Adv. Water Resour., 114, 1-18, https://doi.org/10.1016/j.advwatres.2018.02.008, 2018.

Koster, R. D. and Suarez, M. J.: Modeling the land surface boundary in climate models as a composite of independent vegetation stands, J. Geophys. Res.-Atmos., 97, 2697-2715, 1992.

Koster, R. D., Sud, Y. C., Guo, Z., Dirmeyer, P. A., Bonan, G., Oleson, K. W., Chan, E., Verseghy, D., Cox, P., Davies, H., and Kowalczyk, E.: GLACE: the global land-atmosphere coupling experiment. Part I: overview, J. Hydrometeorol., 7, 590-610, 2006.

Kuss, A. J. M. and Gurdak, J. J.: Groundwater level response in US principal aquifers to ENSO, NAO, PDO, and AMO, J. Hydrol., 519, 1939-1952, 2014.

Landerer, F. W. and Swenson, S. C.: Accuracy of scaled GRACE terrestrial water storage estimates, Water Resour. Res., 48, W04531, https://doi.org/10.1029/2011WR011453, 2012.

Lazenby, M. J., Todd, M. C., Wang, Y., and Chadwick, R.: Future precipitation projections over central and southern Africa and the adjacent Indian Ocean: What causes the changes and the uncertainty?, J. Climate, 31, 4807-4826, 2018.

Liang, X., Xie, Z., and Huang, M.: A new parameterization for surface and groundwater interactions and its impact on water budgets with the variable infiltration capacity (VIC) land surface model, J. Geophys. Res.-Atmos., 108, 8613, https://doi.org/10.1029/2002JD003090, 2003.

MacDonald, A. M., Bonsor, H. C., Dochartaigh, B. É. Ó., and Taylor, R. G.: Quantitative maps of groundwater resources in Africa, Environ. Res. Lett., 7, 024009, https://doi.org/10.1088/17489326/7/2/024009, 2012.

McMahon, T. A., Finlayson, B. L., Haines, A., and Srikanthan, R.: Runoff variability: a global perspective, in: IAHS Publ. no. 168, The Influence of Climate Change and Climatic Variability on the Hydrologic Regime and Water Resources, Proceedings of the Vancouver Symposium, August 1987, Vancouver, 1987.

Meyer, R.: Analysis of groundwater level time series and the relation to rainfall and recharge, Water Resources Commission (South Africa), report number 1323/1/05, Water Research Commission, Pretoria, 2005.

Mishra, V. and Cherkauer, K. A.: Retrospective droughts in the crop growing season: Implications to corn and soybean yield in the Midwestern United States, Agr. Forest Meteorol., 150, 1030 1045, 2010.

Nicholson, S. E.: Long-term variability of the East African 'short rains' and its links to large-scale factors, Int. J. Climatol., 35, 3979-3990, 2015. 
Nicholson, S. E.: Climate and climatic variability of rainfall over eastern Africa, Rev. Geophys., 55, 590-635, 2017.

Owor, M., Taylor, R. G., Tindimugaya, C., and Mwesigwa, D.: Rainfall intensity and groundwater recharge: empirical evidence from the Upper Nile Basin, Environ. Res. Lett., 4, 035009, https://doi.org/10.1088/1748-9326/4/3/035009, 2009.

Ratnam, J. V., Behera, S. K., Masumoto, Y., and Yamagata, T.: Remote effects of El Niño and Modoki events on the austral summer precipitation of southern Africa, J. Climate, 27, 3802-3815, 2014.

Rodell, M., Houser, P. R., Jambor, U. E. A., Gottschalck, J., Mitchell, K., Meng, C. J., ..., and Entin, J. K.: The global land data assimilation system, B. Am. Meteorol. Soc., 85, 381-394, 2004.

Rodell, M., Famiglietti, S., Wiese, D. N., Reager, J. T., Beaudoing, H. K., Landerer, F. W., and Lo, M.-H.: Emerging trends in global freshwater availability, Nature, 557, 651-659, 2018.

Ropelewski, C. F. and Halpert, M. S.: Global and regional scale precipitation patterns associated with the El Niño/Southern Oscillation, Mon. Weather Rev., 115, 1606-1626, 1987.

Russo, S., Marchese, A. F., Sillmann, J., and Immé, G.: When will unusual heat waves become normal in a warming Africa?, Environ. Res. Lett., 11, 054016, https://doi.org/10.1088/17489326/11/5/054016, 2016

SADC: SADC regional situation update on El Nino-induced drought, 12 September 2016, SADC, 12 pp., available at: https://www.sadc.int/files/9514/7403/9132/SADC_Regional_

Situation_Update_No-2_16-09-2016.pdf (last access: 28 March 2019), 2016a.

SADC: SADC Regional Vulnerability Assessment and Analysis Synthesis Report: State of Food Insecurity and Vulnerability in the Southern African Development Community, SADC, 66 pp., available at: https://www.sadc.int/files/9014/7911/5767/SADC_ RVAA-August-Final-Web.pdf (last access: 28 March 2019), 2016b.

Saji, N. H., Goswami, B. N., Vinayachandran, P. N., and Yamagata, T.: A dipole mode in the tropical Indian Ocean, Nature, 401, 360363, https://doi.org/10.1038/43854, 1999.

Scanlon, B. R., Zhang, Z., Save, H., Sun, A. Y., Schmied, H. M., van Beek, L. P. H., Wiese, D. N., Wada, Y., Long, D., Reedy, R. C., Longuevergne, L., Döll, P., and Bierkens, M. F. P.: Global models underestimate large decadal declining and rising water storage trends relative to GRACE satellite data, P. Natl. Acad. Sci. USA, 115, E1080-E1089, https://doi.org/10.1073/pnas.1704665115, 2018.

Schneider, U., Becker, A., Finger, P., Meyer-Christoffer, A., Rudolf, B., and Markus, Z.: GPCC Full Data Reanalysis Version 6.0 at $0.5^{\circ}$ : Monthly Land-Surface Precipitation from RainGauges built on GTS-based and Historic Data, DWD, Germany, https://doi.org/10.5676/DWD_GPCC/FD_M_V6_100, 2011.

Schneider, U., Becker, A., Finger, P., Meyer-Christoffer, A., Ziese, M., and Rudolf, B.: GPCC's new land surface precipitation climatology based on quality-controlled in situ data and its role in quantifying the global water cycle, Theor. Appl. Climatol., 115, 15-40, 2014.

Schumacher, M., Forootan, E., van Dijk, A. I. J. M., Muller Schmied, H., Crosbie, R. S., Kusche, J., and Döll, P.: Improving drought simulations within the Murray-Darling Basin by combined calibration/assimilation of GRACE data into the WaterGAP Global Hydrology Model, Remote Sens. Environ., 204, 212-228, https://doi.org/10.1016/j.rse.2017.10.029, 2018.

Seneviratne, S. I., Corti, T., Davin, E. L., Hirschi, M., Jaeger, E. B., Lehner, I., Orlowsky, B., and Teuling, A. J.: Investigating soil moisture-climate interactions in a changing climate: A review, Earth. Rev., 99, 125-161, https://doi.org/10.1016/j.earscirev.2010.02.004, 2010.

Shamsudduha, M., Taylor, R. G., Jones, D., Longuevergne, L., Owor, M., and Tindimugaya, C.: Recent changes in terrestrial water storage in the Upper Nile Basin: an evaluation of commonly used gridded GRACE products, Hydrol. Earth Syst. Sci., 21, 4533-4549, https://doi.org/10.5194/hess-21-4533-2017, 2017.

Siderius, C., Gannon, K. E., Ndiyoi, M., Opere, A., Batisani, N., Olago, D., Pardoe, J., and Conway, D.: Hydrological response and complex impact pathways of the 2015/2016 El Niño in Eastern and Southern Africa, Earth's Future, 6, 2-22, https://doi.org/10.1002/2017EF000680, 2018.

Smith, T. M., Reynolds, R. W., Peterson, T. C., and Lawrimore, J.: Improvements to NOAA's historical merged land-ocean surface temperature analysis (1880-2006), J. Climate, 21, 2283-2296, 2008.

Swenson, S. and Wahr, J.: Post-processing removal of correlated errors in GRACE data, Geophys. Res. Lett., 33, L08402, https://doi.org/10.1029/2005GL025285, 2006.

Taylor, R. G., Koussis, A. D., and Tindimugaya, C.: Groundwater and climate in Africa - a review, Hydrolog. Sci. J., 54, 655-664, 2009.

Taylor, R. G., Todd, M. C., Kongola, L., Maurice, L., Nahozya, E., Sanga, H., and MacDonald, A. M.: Evidence of the dependence of groundwater resources on extreme rainfall in East Africa, Nat. Clim. Change, 3, 374-378, https://doi.org/10.1038/NCLIMATE1731,, 2013.

van Wyk, E., Van Tonder, G. J., and Vermeulen, D.: Characteristics of local groundwater recharge cycles in South African semiarid hard rock terrains-rainwater input, Water SA, 37, 147-154, https://doi.org/10.4314/wsa.v37i2.65860, 2011.

Vicente-Serrano, S. M., Beguería, S., and López-Moreno, J. I.: A multiscalar drought index sensitive to global warming: the standardized precipitation evapotranspiration index, J. Climate, 23, 1696-1718, 2010.

Villholth, K. G.: Groundwater irrigation for smallholders in SubSaharan Africa - a synthesis of current knowledge to guide sustainable outcomes, Water Int., 38, 369-391, 2013.

Watkins, M. M., Wiese, D. N., Yuan, D. N., Boening, C., and Landerer, F. W.: Improved methods for observing Earth's time variable mass distribution with GRACE using spherical cap mascons, J. Geophys. Res.-Solid, 120, 2648-2671, 2015.

Wiese, D. N., Yuan, D.-N., Boening, C., Landerer, F. W., andWatkins, M. M.: JPL GRACE Mascon Ocean, Ice, and Hydrology Equivalent Water Height, JPL RL05M.1, Ver. 1 PO, DAAC, CA USA, 2015.

Zhao, M., Velicogna, G. A. I., and Kimball, J. S.: Satellite observations of regional drought severity in the continental United States using GRACE-based terrestrial water storage changes, J. Climate, 30, 6297-6308, https://doi.org/10.1175/JCLI-D-160458.1, 2017. 